\title{
Electrical Cochlear Response as an Objective Measure of Hearing Threshold and Hearing Performance Evaluation in Pediatric Cochlear Implant Users
}

\section{Respuesta Coclear Eléctrica como Medida Objetiva del Umbral Auditivo y la Evaluación del Rendimiento Auditivo en Usuarios Pediátricos de Implante Coclear}

\author{
A. K. Quintana-López', N. E. Beltran-Vargas², M. P. Granados-Trejo33, J. M. Cornejo-Cruz \\ Universidad Autonoma Metropolitana, Posgrado en Ingeniería Biomédica \\ ${ }^{2}$ Universidad Autonoma Metropolitana, Cuajimalpa \\ 3Universidad Autonoma Metropolitana, Iztapalapa
}

\begin{abstract}
The difficulties of applying the audiometry in pediatric populations and its methodological limitations in implanted patients have spurred the development of new alternative auditory evaluation methods. This study aimed to show an objective method to estimate hearing thresholds in pediatric cochlear implanted patients through Electrical Cochlear Response (ECR) and to quantify the hearing performance by using an Auditory Skills Questionnaire (ASQ) and a Calibrated Sounds Test (CST) designed on purpose. Eighteen implanted patients, 1-6 years old underwent standard audiometry, ECR, and ASQ in two evaluation sessions T1 and T2. At T2, in addition, patients underwent CST. For patients $\leq 3$ years old (G1), Pure Tone Averages (PTA and PTA $\mathrm{ECR}_{\text {) }}$ showed a statistically significant difference between them at T1 and T2. At T2 improvements in audiometric and ECR thresholds were observed $(p<0.05)$, regarding T1. Patients older than 3 years (G2) had significantly better ASQ and CST scores. CST detection scores at $40 \mathrm{~dB}_{\mathrm{HL}}$ for groups $\mathrm{G} 1$ and G2, 36\% and 70\% respectively, showed a better relationship to ECR thresholds. The relationship observed between ECR thresholds and CST detection scores seems to confirm that ECR brings the feasibility of objective hearing threshold estimation and provides a better frequency resolution than audiometry.
\end{abstract}

KEYWORDS: electro-acoustic test; frequency specificity; intensity calibrated sounds; hearing performance 


\section{RESUMEN}

Las dificultades para la aplicación de la audiometría en la población pediátrica además de sus limitaciones metodológicas en pacientes usuarios de implante coclear, señalan la necesidad de métodos audiométricos alternos. En el presente trabajo se utiliza el potencial eléctrico, denominado Respuesta Coclear Eléctrica (ECR) observado solamente en usuarios de implante coclear, para la estimación de umbrales auditivos prescindiendo de la participación consiente del paciente, además de evaluar el desempeño auditivo mediante un Cuestionario de Habilidades Auditivas (ASQ) y la Prueba de Sonidos Calibrados (CST). A dieciocho participantes de 1 a 6 años, se les practicó Audiometría, ECR y ASQ en dos sesiones, T1 y T2; adicionalmente, en T2 se aplicó CST. En T1 y T2 los promedios de tonos puros, PTA y $\mathrm{PTA}_{\mathrm{ECR}}$, de pacientes $\leq 3$ años (G1), mostraron una diferencia estadísticamente significativa entre ellos. En T2 los umbrales audiométricos y ECR $(p<0.05)$, mejoraron respecto de T1. Pacientes $>3$ años $(\mathrm{G} 2)$ lograron puntuaciones ASQ y CST significativamente mejores. Los puntajes de detección CST a $40 \mathrm{~dB}_{\mathrm{HL}}, \mathrm{G} 1(36 \%)$ y G2(70\%), mostraron mejor relación con los umbrales ECR. Esta relación entre los umbrales ECR y los puntajes de detección CST indican que la ECR permite estimar el umbral de audición, logrando adicionalmente mayor resolución en frecuencia que la audiometría.

KEYWORDS: prueba electro-acústica; especificidad en frecuencia; sonidos calibrados en intensidad; desempeño auditivo

\section{Corresponding author}

TO: Nohra Elsy Beltrán Vargas

INSTITUTION: Universidad Autónoma Metropolitana,

\section{Cuajimalpa}

ADDRESS: Vasco de Quiroga \#4871, Col. Santa Fé,

Del. Cuajimalpa de Morelos, C. P. 05348, CDMX,

Ciudad de México, México

E-MAIL: nbeltran@cua.uam.mx

\section{Received:}

20 August 2020

Accepted:

09 December 2020 


\section{INTRODUCTION}

Today, a technological alternative for patients suffering from profound bilateral sensorineural hearing loss is the cochlear implant (CI) which, based on banded spectrum analysis for extraction of significant voice attributes, obtains an electrical stimulation code which, applied to the patient's hearing system, generates an auditory sensation. The FDA (Food and Drug Administration) recommends using $\mathrm{CI}$ in children from 12 months of age, due to the difficulty of performing behavioral hearing tests in younger patients. This is a limitation when seeking successful rehabilitation in the implanted patients, considering that the critical period for language acquisition comprises the first years of life ${ }^{[1][2][3]}$.

Four to six weeks following implant surgery, CI is programmed for the first time, starting the process of customizing the device to the patient's needs, in order to achieve useful, safe, and comfortable hearing. The different parameters involved in CI programming include establishing the dynamic range of electrical stimulation current in each intracochlear electrode, delimited by the minimum (T) and maximum (M) levels corresponding to the threshold and maximum tolerable auditory sensation, respectively ${ }^{[4]}$. In clinical practice these current levels are determined by observing the patient's auditory behavior in response to the electrical stimulation provided for a limited number of electrodes. This behavioral CI fitting can be more difficult in pediatric patients who lack the communication skills needed to obtain reliable feedback information.

This scenario has led to the use of electrophysiological methodologies such as Brainstem Auditory Evoked Potentials (BAEPs) [5] [6], the Electric Stapedial Reflex Threshold (ESRT) ${ }^{[7][8][9][10]}$, and the Electrically-Evoked Compound Action Potential (ECAP) [5] [9] [10] [11], to estimate $\mathrm{T}$ and $\mathrm{M}$ current levels for the electrode array. Of these methodologies, ECAP is the most used because it can be recorded for selected electrodes during or after implantation surgery ${ }^{[12]}$.
Unfortunately, neither ECAP nor other electrophysiological methodologies mentioned previously, allow the estimation of hearing thresholds. The audiometry is the only clinical test available to determine hearing thresholds for a number of standardized frequencies [13] [14] [15] [16], which requires the conscious participation of the patient.

Audiometry results are reliable in patients older than 4 years old, while in younger patients it is difficult to perform because they frequently do not present perceptible behavioral changes. It is even more difficult to observe the changes in implanted patients, especially in their first CI programming session because they are not familiar with the use of the device ${ }^{[17]}$.

Furthermore, standard audiometry was not originally designed for implanted users. Test standardized frequencies set does not consider the band pass filter number for the spectral analysis that CI sound processor performs on the external input sound. The number of the band pass filter depends on the number of active electrodes and the IC manufacturer. Therefore, if any audiometry test frequency fall outside the band-pass filter bandwidth, corresponding to a certain intracochlear electrode, the hearing threshold may not be evaluated correctly.

Despite audiometry application difficulties and limitations in implanted pediatric patients, this test is used as a guide to readjust stimulation current level in the intracochlear electrode array, in order to lead the patient from an auditory status equivalent to profound deafness to normal hearing. The methodological limitations to determine the optimal $\mathrm{M}$ and $\mathrm{T}$ current levels across the electrode array, by using electrical stimulation tests like ECAP, as well as the difficulties in estimating the hearing thresholds due to the adjustment of the current levels, especially in pediatric patients, has generated the need to develop new alternative methods to evaluate hearing. 
Our research group at the Metropolitan Autonomous University (UAM) Audiology Laboratory has developed a test called Electrical Cochlear Response (ECR) ${ }^{[18]}$, as an alternative method for hearing threshold estimation in implanted pediatric patients. ECR measures the electrical response of the auditory nerve due to electric stimulation every time CI processes an incoming external sound. The ECR considers the auditory nerve portion responsiveness to the electrical current involved with each intracochlear electrode. For a given dynamic range of electrical current in an intracochlear electrode, ECR allows establishing the minimum sound intensity level for which auditory nerve portion near to intracochlear electrode generates a threshold electrical response.

Through individual electrode current adjusting, ECR test can help to estimate the auditory threshold at each of the intracochlear electrodes. This is done by quantifying the change in amplitude of the ECR due to variations in the sound intensity level of the input sound.

Previous ECR results have shown that the activation profile of the intracochlear electrodes follows the audiometric threshold profile ${ }^{[19]}$. These results have shown the feasibility of estimating the patient's hearing thresholds based on ECR, which is independent of the age, general health condition, previous time of use, or brand of the CI.

On the other hand, considerable efforts have been made in the clinical field to establish an auditory-verbal rehabilitation program for pediatric CI users, by using a standardized set of tests that include questionnaires about child' hearing abilities development, and evaluation of speech and sounds discrimination ${ }^{[20][21]}$. However, up to now, there are no standardized methodologies to quantify the patient's hearing performance during the period of adaptation to the device.
The purpose of this work is to show the use of ECR to estimate hearing thresholds in implanted pediatric patients and to evaluate hearing performance through the application of a set of tests designed to assess the patient's hearing abilities (see Table 1).

\section{MATERIALS AND METHODS}

\section{Population}

We included a group of 25 pre-lingual CI users between 1.4-6.6 years of age, who underwent CI surgery at the National Institute of Rehabilitation (INR), in Mexico City. Patients were diagnosed with bilateral profound sensorineural deafness and used hearing aids for at least six months previous to implantation surgery. All patients had a full insertion of the electrode array. Patients with neurological disease or ossified cochlea, and those without audiometry were excluded. Patients who did not complete the follow-up period were eliminated. The patient's parents accepted to wake up their children around 10 hours before ECR test. Ethical Research Committee of INR approved and supervised the study complied with all applicable research and ethical standards and laws followed by the Declaration of Helsinki principles. All patients' parents signed informed consent.

Two evaluation sessions were considered, T1: 1.5 to 9 months after CI implantation, and T2: 7 months after T1. The Figure 1 shows a flow diagram of the procedure used for patient's hearing evaluation in each session.

\section{Tests}

Tests were performed at the INR audiology service in

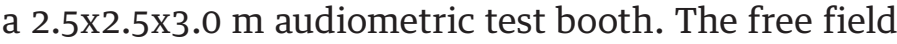
was calibrated according to ISO 389-7 Standard using a B\&K 2235 sound meter, B\&K 1625 filter, and a B\&K 4230 microphone calibrator. The free field audiometry and ECR test were obtained in two different and successive days. Audiometry was performed using an Interacoustics clinical audiometer AC-40, while the 


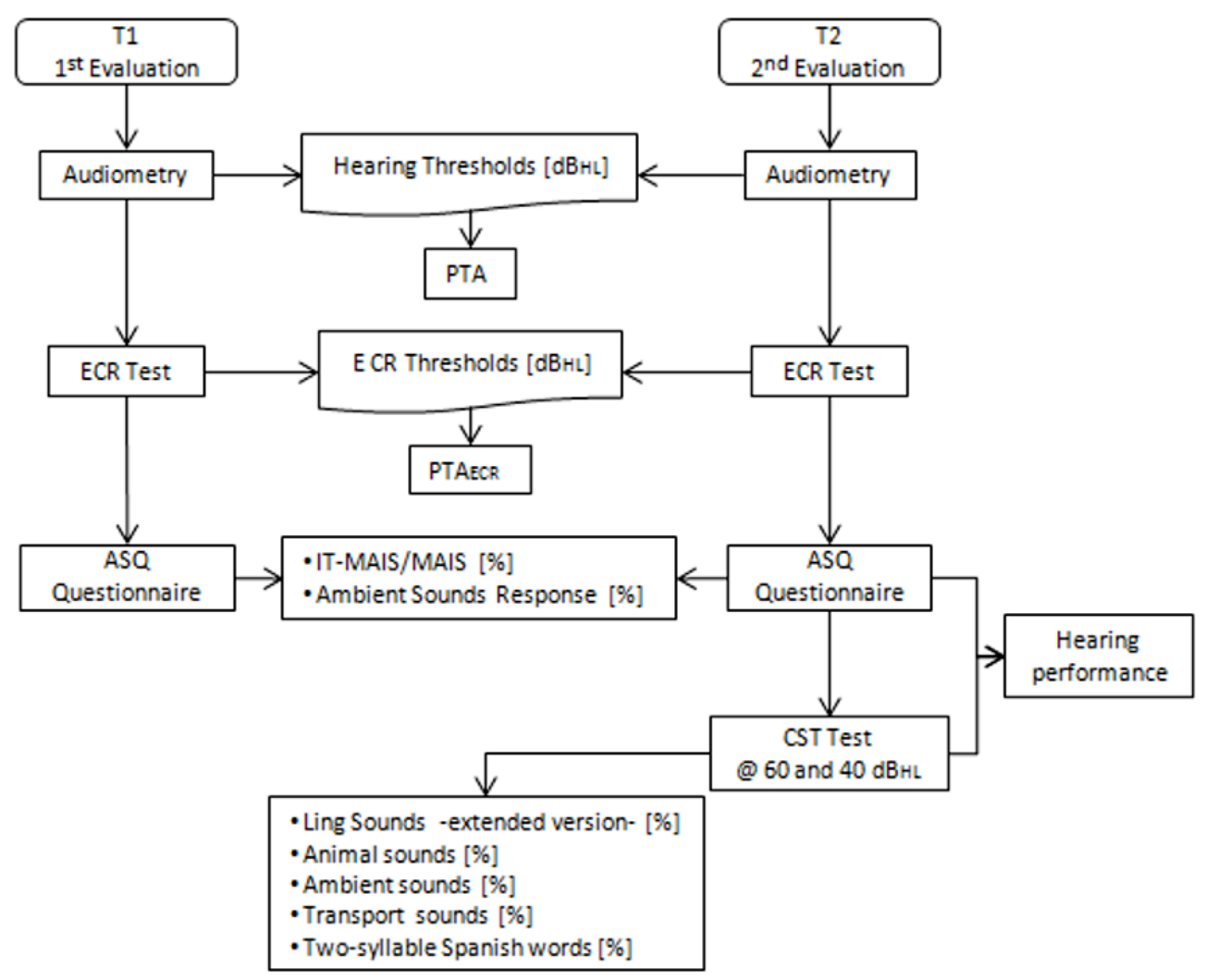

FIGURE 1. Flow diagram procedure used for patient's hearing evaluation in T1 and T2 sessions.

patient was wearing the CI, seated a meter away from the loudspeaker. Pure Tone Average (PTA) was calculated in the frequency range of 500 to $2000 \mathrm{~Hz}$ to determine the patient's hearing level ${ }^{[15]}$.

A prototype of ECR Monitor developed by the UAM Audiology Laboratory jointly with the company Innovamedica was used to obtain ECR. The prototype consists of one module to generate and reproduce sound stimuli, and other to acquire EEG, and a PC platform with software which synchronizes and organizes the acquisition of EEG with the reproduction of the stimuli (Figure 2).

Two recording EEG channels with A1(-), A2(-), $\mathrm{Cz}(+)$ and $\mathrm{FPz}(\mathrm{GND})$ according to $10-20$ system ${ }^{[22]}$, observing an electrode-skin impedance $<5 \mathrm{k} \Omega$ at $100 \mathrm{~Hz}$ were used. One hundred 50 ms EEG epochs were averaged, previously filtered with a second-order Butterworth low-pass filter of 0.1 to $300 \mathrm{~Hz}$ with cutoff slope of 12 $\mathrm{dB} /$ Octave, zero phase, $\pm 10 \mu \mathrm{V}$ artifact rejection window, and a sampling frequency of $20 \mathrm{kHz}$.

The waveform of ECR response $\left(^{*}\right)$ is shown in Figure 2 for a stimulation tone pip of $1278 \mathrm{~Hz}$ (central frequency assigned to the intracochlear electrode number eight). The increase in the ECR amplitude and the decrease in latency are due to the increase in the intensity of the tone pip. The ECR threshold is defined as the minimum intensity for robust ECR detection.

During the ECR test the patient remained asleep on a cot with the head facing a loudspeaker positioned at a distance of one meter, with CI operating under everyday usage conditions, according to the CI programming parameters previously defined by the audiologist. The test was performed in the presence of the patient's parents and supervised by the audiologist. 


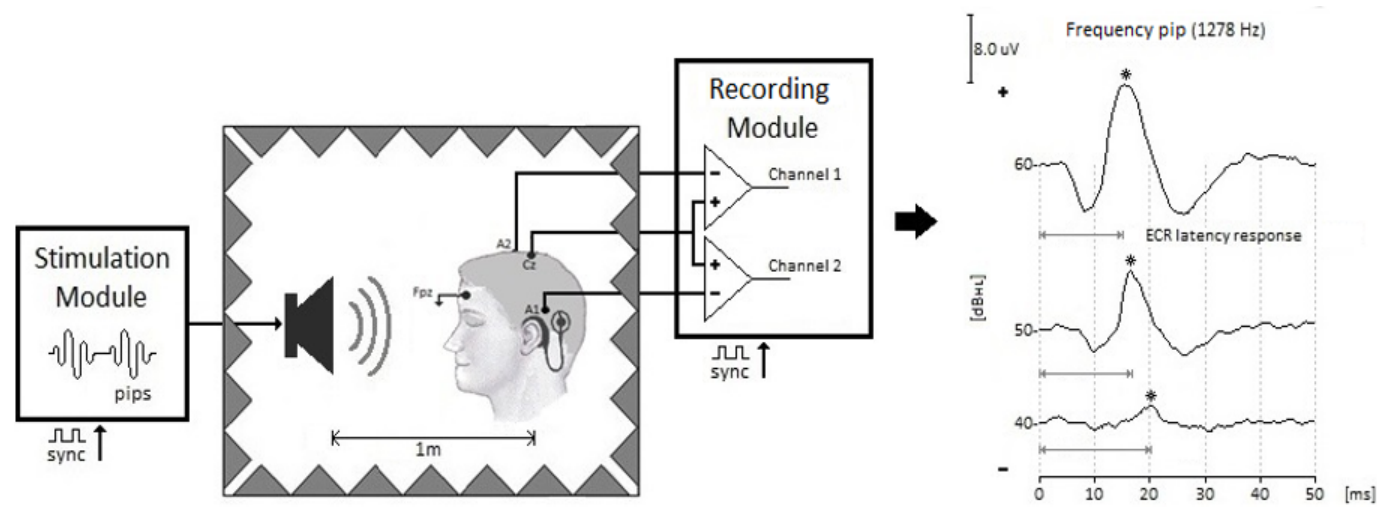

FIGURE 2. Block diagram of the system for ECR acquisition. The tone pip is generated in the

Stimulation Module and sent to the patient while the patient is asleep inside the audiometric test booth.

Two channels of EEG recording are used in the Acquisition Module. ECR waveforms obtained from an average of 100 EEG epochs due to a tone pip of $1278 \mathrm{~Hz}$, for an increasing intensity level.

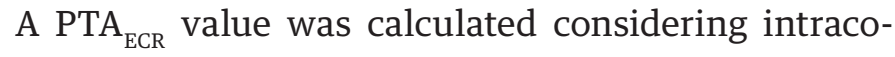
chlear electrode central frequencies in the frequency range of 500 to $2000 \mathrm{~Hz}$ (540, 642, 762, 906, 1076, 1278, 1518 and $1803 \mathrm{~Hz}$ ). Patients' hearing level was classified as normal (0-20 $\mathrm{dB}_{\mathrm{HL}}$ ), mild deafness (20-40 $\left.\mathrm{dB}_{\mathrm{HL}}\right)$, moderate deafness $\left(40-60 \mathrm{~dB}_{\mathrm{HL}}\right)$, severe deafness $\left(60-80 \mathrm{~dB}_{\mathrm{HL}}\right)$, and profound deafness (>80 dB $\left.\mathrm{dL}_{\mathrm{HL}}\right)$ ${ }^{[9]}$. Additional intermediate audiometric threshold values were interpolated to compare audiometry with ECR test result frequency by frequency.

Once ECR test finished, patients' parents answered the ASQ to provide information about the child's ability to use the CI in daily situations and the ability to detect, identify, and repeat 18 ambient sounds, as indicated in Table 1. Items evaluated were taken from the IT-MAIS/MAIS scale and the LiP Profile ${ }^{[20] ~[23] . ~ T h e ~}$ CST was designed to evaluate the patient's ability to detect, identify, and repeat 6 seconds duration real sounds and two-syllable Spanish words (Table 1).

All the CST items were normalized in amplitude and grouped in the following five groups: 1 . An extended version of Ling sounds, which include eight representative phonemes of the speech spectrum ${ }^{[1]}{ }^{[24]} ; 2$. Thirteen animal sounds; 3. Seven transportation sounds; 4. Ten ambient sounds ${ }^{[1]}{ }^{[25]}$; 5. Fourteen two-syllable Spanish words ${ }^{[1]}$. Ling sounds -extended version- and two-syllable Spanish words were recorded in a soundproof chamber at INR Audiology Service.

During CST, the patient remained seated at a distance of one meter from the loudspeaker. Three different sessions of 40 minutes were necessary to complete CST. At each session, cards with allusive images to sounds were given to the patient to keep their attention during the test. Each item was randomly played up to three times, starting at $60 \mathrm{~dB}_{\mathrm{HL}}$, while the therapist registered the patient's responses. The test was performed in the presence of the patients' parents, under the everyday CI program mode.

ASQ and CST scores achieved by patients were used to quantify the hearing performance at the end of the follow-up period. Table 1 details all test items and the evaluation criteria considered to achieve a hearing performance of $100 \%$.

\section{Statistical analysis}

The dependent t-test was used to evaluate changes in audiometry and ECR thresholds for all the patients between sessions $\mathrm{T} 1$ and $\mathrm{T} 2$. The independent t-test was 
TABLE 1. Itemize of test items taken into account to evaluate the hearing performance in implanted patients.

\begin{tabular}{|c|c|c|c|}
\hline \multicolumn{2}{|l|}{ Items } & \multirow[t]{2}{*}{ Score $[\%]$} & \multirow[t]{2}{*}{ Score assignment criteria } \\
\hline \multicolumn{2}{|r|}{ Auditory Skills Questionnaire } & & \\
\hline 1. IT-MAIS/MAIS & $\begin{array}{l}\text { Does the child ... } \\
\text { 1. ask the CI is turned on, off or the child turned it } \\
\text { on itself? } \\
\text { 2. report the CI does not work? } \\
\text { 3. respond to its name without visual cues in: silent } \\
\text { environment? } \\
\text { 4. noise environment } \\
\text { 5. respond spontaneously to the house sounds? } \\
6 . \text { respond spontaneously in unknown } \\
\text { environments? } \\
\text { 7. recognize auditory cues in the school? } \\
\text { 9. distinguish different voices? } \\
\text { 10. make a difference between voiced and voiceless? }\end{array}$ & 15 & $\begin{array}{l}\text { At the beginning of the study, } 89 \% \text { of } \\
\text { patients still had not acquired the } \\
\text { necessary skills to cooperate with the } \\
\text { sound detection task, so to know } \\
\text { something about children's hearing } \\
\text { abilities was through this standardized } \\
\text { test. }\end{array}$ \\
\hline $\begin{array}{ll}\text { 2. Ambient Sounds Response } \\
* \quad \text { Detection } \\
* \quad \text { Identification } \\
* \quad \text { Repetition }\end{array}$ & $\begin{array}{l}\text { bell, car, bird, train, whisper, baby crying, truck, } \\
\text { siren, plane, faucet, barking, conversation, blender, } \\
\text { firework, helicopter, telephone, motorcycle, knock- } \\
\text { on-the-door. }\end{array}$ & 15 & $\begin{array}{l}\text { Known sounds by children provided by } \\
\text { their parents and therapists. }\end{array}$ \\
\hline \multicolumn{4}{|c|}{ Calibrated Sound Test @60 and $40 \mathrm{~dB}_{\mathrm{HL}}$-Detection, Identification and Repetition- } \\
\hline $\begin{array}{l}\text { 1. Ling Sounds } \\
\text {-extended version- }\end{array}$ & $/ \mathrm{a} /, \quad / \mathrm{u} /, \quad / \mathrm{i} /, \quad / \mathrm{m} /, \quad / \mathrm{s} /, \quad / \mathrm{sh} /, \quad / \mathrm{e} /, \quad / \mathrm{o} /$ & 40 & $\begin{array}{l}\text { Based on a standardized test used on CI } \\
\text { programming and rehabilitation therapy } \\
\text { and this is the first time that recorded } \\
\text { phonemes are used. }\end{array}$ \\
\hline 2. Animal sounds & $\begin{array}{l}\text { cat, dog, pig, cow, bird, lion, duck, sheep, horse, } \\
\text { mouse, rooster, chicken, donkey. }\end{array}$ & 10 & $\begin{array}{l}\text { Recorded animal and ambient sounds are } \\
\text { used to evaluate the hearing perception } \\
\text { of implanted patients for the first time. }\end{array}$ \\
\hline 3. Ambient sounds & $\begin{array}{l}\text { bell, clock, siren, faucet, blender, fireworks, telephone, } \\
\text { conversation, baby crying, knock-on-the-door. }\end{array}$ & 10 & \\
\hline 4. Transport sounds & car, train, truck, plane, ship, helicopter, motorcycle. & 5 & $\begin{array}{l}\text { Transport recorded sounds presented } \\
\text { similar spectral content. }\end{array}$ \\
\hline 5. Two-syllable Spanish words & $\begin{array}{l}\text { ala (wing), caja (box), cama (bed), capa(cape), } \\
\text { cara(face), casa (house), gafa (glasses), jarra } \\
\text { (tankard), hada (fairly), lava (wash), maga } \\
\text { (magician), rana (frog), rata (rat), vaca (cow). }\end{array}$ & 5 & $\begin{array}{l}\text { Difficulty in evaluating these words in a } \\
\text { recorded way due to patients' } \\
\text { unfamiliarity with some of them. }\end{array}$ \\
\hline Hearing performance & & 100 & \\
\hline
\end{tabular}

used to evaluate differences between PTA and PTA ${ }_{\mathrm{ECR}}$ by gender or age, at $\mathrm{T} 1$ and $\mathrm{T} 2$ sessions. The performance tests were evaluated by non-parametric analysis because the data did not show a normal distribution.

ASQ scores by gender and age were analyzed using the Mann-Whitney $U$ test at each evaluation session. Scores obtained between $\mathrm{T} 1$ and $\mathrm{T} 2$ sessions were analyzed using the Wilcoxon rank-sum test. The CST scores were compared in patients grouped by age using the Mann-Whitney U test. The data were analyzed with NCSS V.9.0.5 ${ }^{[26]}$, considering $p<0.05$ as significant value. Results are presented in terms of mean \pm standard deviation (SD) and percentages.

\section{RESULTS AND DISCUSSION}

Of the 25 patients initially included, seven were eliminated because they did not complete the follow-up period. Two of them experienced problems with the implant and five did not complete the battery of tests. The average age of the 18 patients included in the analysis (9 girls and 9 boys) was 3.2 \pm 0.9 (1.8-5.7) years. The average auditory age (elapsed time between CI activation and ECR recording) was 7.2 months. Information about the patients is presented in Table 2.

Figure 3 shows the mean thresholds values for audiometry and ECR for all patients in sessions T1 and T2. A significant decrease in these thresholds is observed 
TABLE 2. Patients included in the analysis, users of IC brand Advanced Bionics, model Hires $90 \mathrm{~K} / \mathrm{HiFocus}$ with complete insertion of intracochlear electrodes.

\begin{tabular}{|c|c|c|c|c|c|c|c|c|c|c|}
\hline \multirow[b]{2}{*}{ 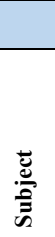 } & \multirow[b]{2}{*}{ 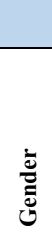 } & \multirow[b]{2}{*}{ 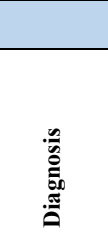 } & \multirow[b]{2}{*}{ 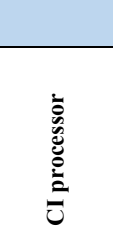 } & \multicolumn{3}{|c|}{ T1 Evaluation } & \multicolumn{3}{|c|}{ T2 Evaluation } & \multirow[b]{2}{*}{ 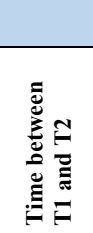 } \\
\hline & & & & 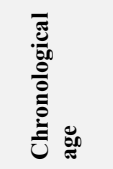 & 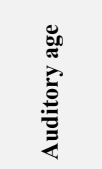 & 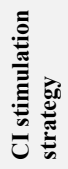 & 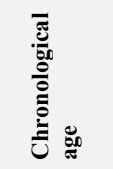 & 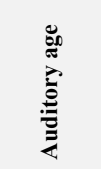 & 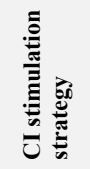 & \\
\hline S1 & $\mathrm{F}$ & BPSD & Harmony & $3 y$ & $7 \mathrm{~m}$ & $\mathrm{HS} / \mathrm{F}$ & $4 y, 2 m$ & $1 \mathrm{y}, 5 \mathrm{~m}$ & $\mathrm{HS} / \mathrm{F}$ & $1 \mathrm{y}, 2 \mathrm{~m}$ \\
\hline S2 & M & BSCMD & PSP & $3 \mathrm{y}, 8 \mathrm{~m}$ & $5 \mathrm{~m}$ & $\mathrm{HP} / \mathrm{F}$ & $4 \mathrm{y}, 7 \mathrm{~m}$ & $1 \mathrm{y}, 1 \mathrm{~m}$ & $\mathrm{HS} / \mathrm{F}$ & $11 \mathrm{~m}$ \\
\hline S3 & M & BSCMD & Harmony & $3 \mathrm{y}, 8 \mathrm{~m}$ & $1 \mathrm{~m}$ & $\mathrm{HP} / \mathrm{F}$ & $5 y$ & $1 \mathrm{y}, 2 \mathrm{~m}$ & $\mathrm{HP} / \mathrm{F}$ & $1 \mathrm{y}, 4 \mathrm{~m}$ \\
\hline S4 & $\mathrm{F}$ & BPSD & Harmony & $1 \mathrm{y}, 10 \mathrm{~m}$ & $4 \mathrm{~m}$ & $\mathrm{HS} / \mathrm{F}$ & $2 \mathrm{y}, 8 \mathrm{~m}$ & $1 \mathrm{y}, 1 \mathrm{~m}$ & $\mathrm{HP} / \mathrm{F}$ & $10 \mathrm{~m}$ \\
\hline S5 & F & BPSD & Harmony & $3 \mathrm{y}, 6 \mathrm{~m}$ & $10 \mathrm{~m}$ & $\mathrm{HP} / \mathrm{F}$ & $4 y, 5 \mathrm{~m}$ & $1 \mathrm{y}, 7 \mathrm{~m}$ & $\mathrm{HP} / \mathrm{F}$ & $11 \mathrm{~m}$ \\
\hline S6 & F & BPSD & Harmony & $3 \mathrm{y}, 2 \mathrm{~m}$ & $4 \mathrm{~m}$ & $\mathrm{HP} / \mathrm{F}$ & $3 \mathrm{y}, 11 \mathrm{~m}$ & $11 \mathrm{~m}$ & $\mathrm{HP} / \mathrm{F}$ & $9 \mathrm{~m}$ \\
\hline S7 & M & BPSD & Harmony & $2 y, 4 \mathrm{~m}$ & $4 \mathrm{~m}$ & $\mathrm{HP} / \mathrm{F}$ & $2 \mathrm{y}, 11 \mathrm{~m}$ & $10 \mathrm{~m}$ & $\mathrm{HP} / \mathrm{F}$ & $7 \mathrm{~m}$ \\
\hline S8 & M & BPSD & Harmony & $3 \mathrm{y}, 4 \mathrm{~m}$ & $7 \mathrm{~m}$ & $\mathrm{HP} / \mathrm{F}$ & $4 y$ & $1 \mathrm{a}, 2 \mathrm{~m}$ & Hires-P & $8 \mathrm{~m}$ \\
\hline S9 & M & BSCMD & Harmony & $3 y$ & $2 \mathrm{~m}$ & $\mathrm{HP} / \mathrm{F}$ & $3 \mathrm{y}, 7 \mathrm{~m}$ & $7 \mathrm{~m}$ & $\mathrm{HP} / \mathrm{F}$ & $7 \mathrm{~m}$ \\
\hline $\mathrm{S} 10$ & F & BSCMD & Harmony & $2 \mathrm{y}, 7 \mathrm{~m}$ & $2 \mathrm{~m}$ & $\mathrm{HP} / \mathrm{F}$ & $3 \mathrm{y}, 2 \mathrm{~m}$ & $8 \mathrm{~m}$ & $\mathrm{HP} / \mathrm{F}$ & $7 \mathrm{~m}$ \\
\hline S11 & M & BPSD & Harmony & $3 \mathrm{y}, 5 \mathrm{~m}$ & $4 \mathrm{~m}$ & $\mathrm{HP} / \mathrm{F}$ & $4 y, 2 \mathrm{~m}$ & $11 \mathrm{~m}$ & Hires-P & $9 \mathrm{~m}$ \\
\hline $\mathrm{S} 12$ & M & BPSD & Harmony & $2 \mathrm{y}, 5 \mathrm{~m}$ & $6 \mathrm{~m}$ & $\mathrm{HP} / \mathrm{F}$ & $3 \mathrm{y}, 1 \mathrm{~m}$ & $1 \mathrm{y}$ & $\mathrm{HP} / \mathrm{F}$ & $8 \mathrm{~m}$ \\
\hline $\mathrm{S} 13$ & F & BPSD & PSP & $5 \mathrm{y}, 8 \mathrm{~m}$ & $1 \mathrm{y}, 11 \mathrm{~m}$ & $\mathrm{HP} / \mathrm{F}$ & $6 y, 7 \mathrm{~m}$ & $2 \mathrm{y}, 6 \mathrm{~m}$ & $\mathrm{HP} / \mathrm{F}$ & $11 \mathrm{~m}$ \\
\hline S14 & $\mathrm{F}$ & BPSD & Harmony & $3 \mathrm{y}, 6 \mathrm{~m}$ & $5 \mathrm{~m}$ & $\mathrm{HP} / \mathrm{F}$ & $4 y, 4 \mathrm{~m}$ & $1 \mathrm{y}, 1 \mathrm{~m}$ & $\mathrm{HP} / \mathrm{F}$ & $10 \mathrm{~m}$ \\
\hline S15 & M & BSCMD & Neptuno & $1 \mathrm{y}, 11 \mathrm{~m}$ & $1 \mathrm{~m}$ & $\mathrm{HP} / \mathrm{F}$ & $2 \mathrm{y}, 6 \mathrm{~m}$ & $7 \mathrm{~m}$ & $\mathrm{HS} / \mathrm{F}$ & $7 \mathrm{~m}$ \\
\hline S16 & F & BSCMD & Harmony & $3 \mathrm{y}, 5 \mathrm{~m}$ & $1 \mathrm{y}, 7 \mathrm{~m}$ & $\mathrm{HP} / \mathrm{F}$ & $4 \mathrm{y}, 1 \mathrm{~m}$ & $2 \mathrm{y}, 1 \mathrm{~m}$ & $\mathrm{HP} / \mathrm{F}$ & $8 \mathrm{~m}$ \\
\hline S17 & M & BPSD & Harmony & $4 \mathrm{y}, 4 \mathrm{~m}$ & $1 \mathrm{y}, 6 \mathrm{~m}$ & $\mathrm{HP} / \mathrm{F}$ & $5 \mathrm{y}$ & $2 \mathrm{y}$ & $\mathrm{HP} / \mathrm{F}$ & $8 \mathrm{~m}$ \\
\hline S18 & $\mathrm{F}$ & BPSD & Harmony & $2 \mathrm{y}, 10 \mathrm{~m}$ & $1 \mathrm{~m}$ & $\mathrm{HP} / \mathrm{F}$ & $3 y, 7 \mathrm{~m}$ & $8 \mathrm{~m}$ & $\mathrm{HS} / \mathrm{F}$ & $9 \mathrm{~m}$ \\
\hline
\end{tabular}

Auditory age: $\mathrm{CI}$ use time elapsed from $\mathrm{CI}$ activation. BSCMD: Bilateral Sensorineural Conductive Mixed Deafness. BPSD: Bilateral Profound Sensorineural Deafness.

HP/F: Hires-P w/Fidelity 120.

HS/F: Hires-S w/Fidelity 120.

in $\mathrm{T} 2$ in relation to $\mathrm{T} 1(p<0.05), 11 \pm 2 \mathrm{~dB}_{\mathrm{HL}}$ and $7 \pm 3 \mathrm{~dB}_{\mathrm{HL}}$, respectively, indicating an improvement in hearing thresholds over time. ECR thresholds were obtained at lower intensity than audiometry, $7 \mathrm{~dB}_{\mathrm{HL}}$ at $\mathrm{T} 1 \mathrm{y} 3 \mathrm{~dB}_{\mathrm{HL}}$ at T2, on average. Significant differences $(p<0.05)$ were observed for 1076, 1278 and $6665 \mathrm{~Hz}$ in T1. In both testing sessions, the ECR threshold values showed less dispersion $\left(\approx 10 \mathrm{~dB}_{\mathrm{HL}}\right)$ than the audiometry $\left(\approx 20 \mathrm{~dB}_{\mathrm{HL}}\right)$.

Audiometric and ECR thresholds, PTA, PTA ${ }_{\mathrm{ECR}}$, ASQ and CST scores did not show significant differences when analyzed by gender. For the analysis by chronological age, patients were divided into 2 groups: 3 years and younger $(\mathrm{G} 1 ; \mathrm{n}=8)$ and older than 3 years $(\mathrm{G} 2 ; \mathrm{n}=10)$.
Table 3 shows significant PTA differences between G1 and G2 groups in the two sessions, with lower values in G2; while the PTA ${ }_{\mathrm{ECR}}$ do not show significant changes between $\mathrm{G} 1$ and $\mathrm{G} 2$. In both sessions, $\mathrm{PTA}_{\mathrm{ECR}}$ values were lower than PTA values for G1 group $(p<0.05) ; 22 \mathrm{~dB}_{\mathrm{HL}}$ at T1 session, and $13 \mathrm{~dB}_{\mathrm{HL}}$ at T2 session. On the other hand, G2 group did not show significant differences between PTA and PTA ${ }_{\mathrm{ECR}}$ values, 4 $\mathrm{dB}_{\mathrm{HL}}$ at $\mathrm{T} 1(p=0.37)$ and $5 \mathrm{~dB}_{\mathrm{HL}}$ at T2 $(p=0.29)$.

Regarding ASQ, G1 group improved significantly their scores $(p<0.05)$ from T1 to T2 session for IT-MAIS/ MAIS and Ambient Sounds Response -Detection-. The scores improvement for Identification $(p=0.13)$ and 

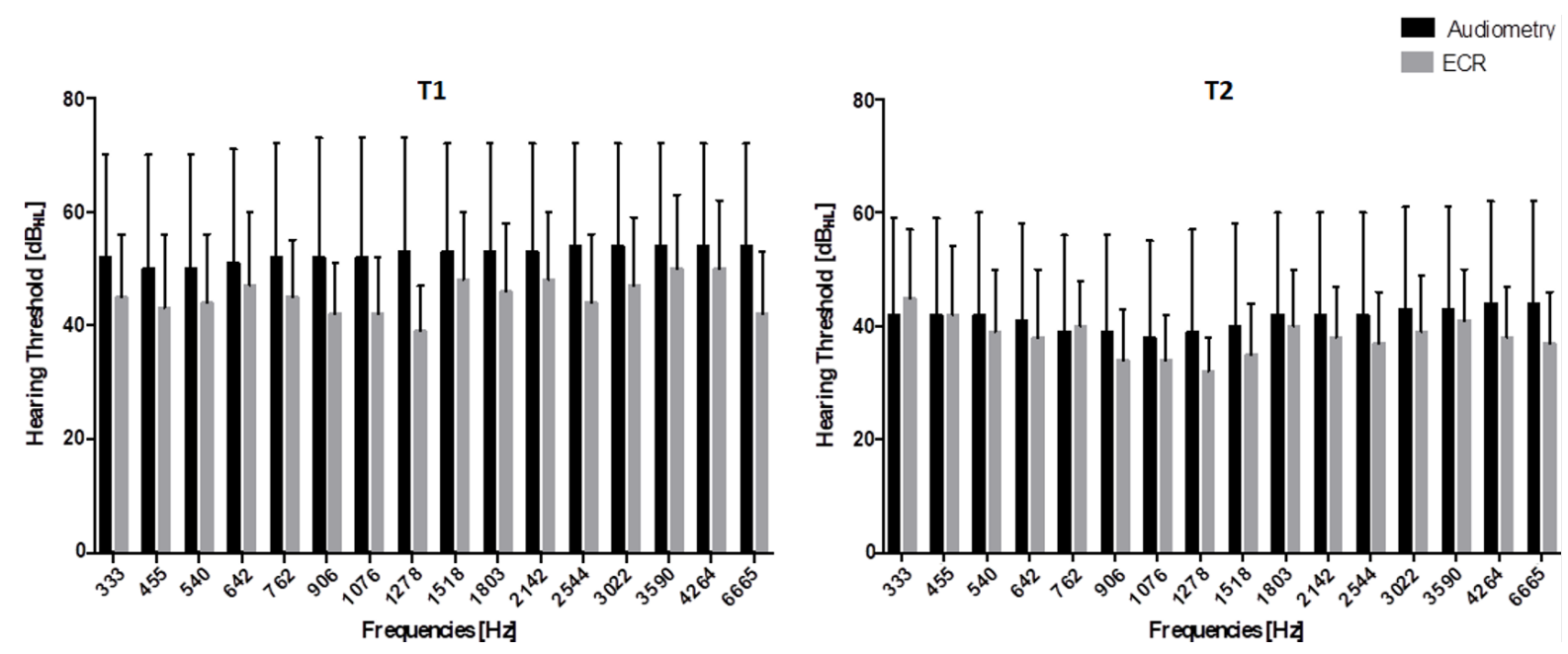

FIGURE 3. Mean and standard deviation values of the audiometric and ECR thresholds by frequency obtained from 18 patients, ages $3.2 \pm 0.9$ years, at $\mathrm{T} 1$ and $\mathrm{T} 2$ sessions.

Repetition ( $p=0.23)$ ambient sounds were not significant. For G2 group there was not a score significantly improvement for any ASQ items. Better scores were obtained by G2 group at T1 and T2 sessions and only for Identification, significantly differences between groups were found at both sessions.

Figure 4 shows mean audiometric and ECR thresholds for both patient groups at T2 session when patients' cooperation got better allowing reliable audiometry. For G1 group ECR had lower threshold and less dispersion than audiometry. Significant differences $(p<0.05), 17 \pm 2$ $\mathrm{dB}_{\mathrm{HL}}$ on average, between audiometric and ECR thresholds for frequencies above $1278 \mathrm{~Hz}$ were observed. For G2 group, audiometry and ECR had lower threshold than G1 group without significant differences between tests. Audiometry showed lower threshold, $5 \pm 3 \mathrm{~dB}_{\mathrm{HL}}$ on average, and greater variability than ECR. In T2, after more than a year wearing the CI in most patients, the CST was evaluated to quantify the hearing performance, once the children became familiar with the use of the CI. G2 had better CST detection scores than G1.
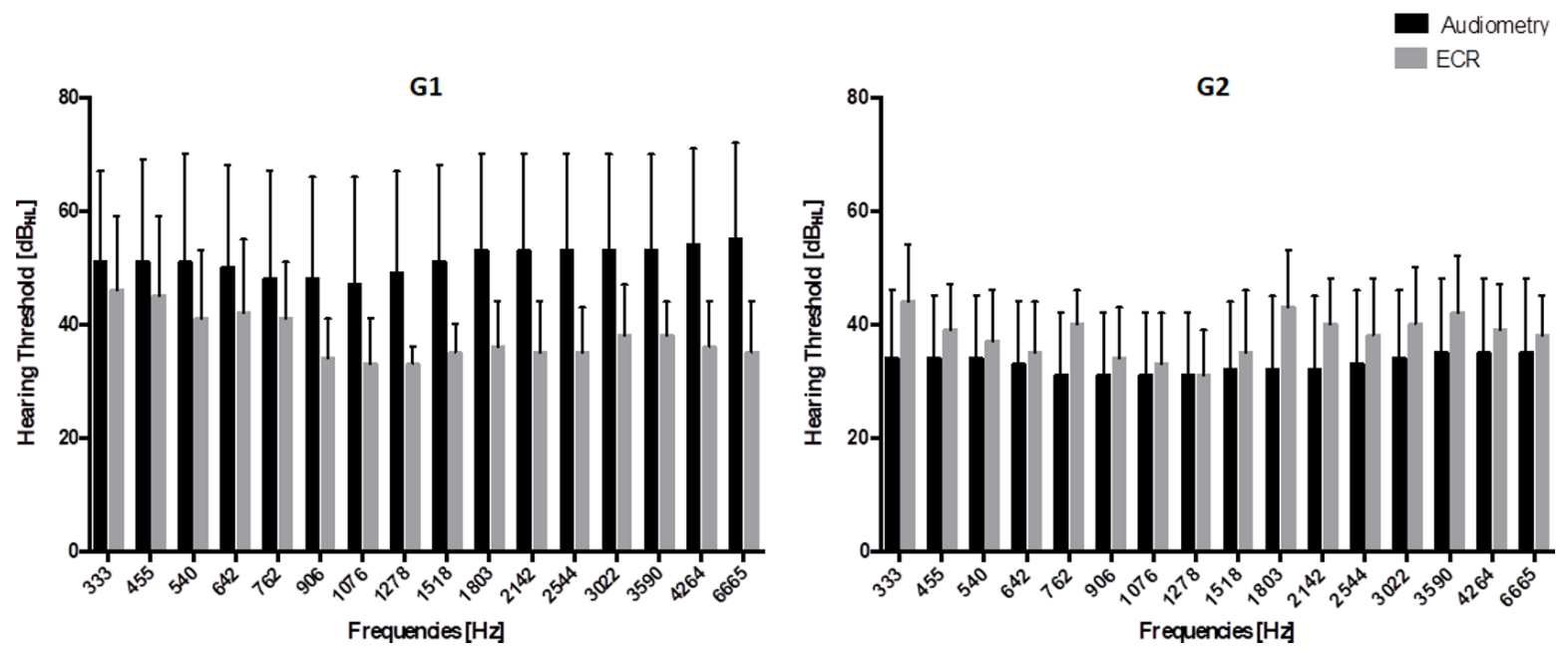

FIGURE 4. Audiometric and ECR thresholds of patients 3 years of age or younger (group G1), and patients older than 3 years (group G2), in session $\mathrm{T} 2$. 
TABLE 3. Features of the patients in sessions T1 and T2.

\begin{tabular}{|c|c|c|c|c|c|c|}
\hline \multirow{2}{*}{$\begin{array}{l}\text { Evaluation Session } \\
\text { Patient group }\end{array}$} & \multicolumn{3}{|c|}{ T1 } & \multicolumn{3}{|c|}{ T2 } \\
\hline & $\mathrm{G} 1(\mathrm{n}=8)$ & $\mathrm{G} 2(\mathrm{n}=10)$ & $p$ & G1 $(n=8)$ & $\mathrm{G} 2(\mathrm{n}=10)$ & $p$ \\
\hline \multicolumn{7}{|l|}{ Age [Years] } \\
\hline Chronological & $2.5 \pm 0.5(1.8-3)$ & $3.8 \pm 0.7(3.2-5.7)$ & $0.05 *$ & $3.2 \pm 0.6(2.4-4.2)$ & $4.6 \pm 0.8(3.9-6.6)$ & $0.05 *$ \\
\hline Auditory & $0.3 \pm 0.1(0.1-0.5)$ & $0.8 \pm 0.6(0.1-1.9)$ & $0.05 *$ & $0.9 \pm 0.3(0.6-1.4)$ & $1.5 \pm 0.6(0.96-2.5)$ & $0.05 *$ \\
\hline \multicolumn{7}{|l|}{ Hearing level $\left[\mathrm{dB}_{\mathrm{HL}}\right]$} \\
\hline$P T A$ & $68 \pm 13(50-90)$ & $40 \pm 11(18-53)$ & $0.05 *$ & $51 \pm 17(19-80)$ & $33 \pm 12(23-63)$ & $0.05^{*}$ \\
\hline PTAECR & $46 \pm 10(32-61)$ & $44 \pm 10(33-66)$ & 0.74 & $38 \pm 6(27-44)$ & $38 \pm 7(27-52)$ & 0.98 \\
\hline \multicolumn{7}{|c|}{ Auditory Skills Questionnaire [\%] } \\
\hline 1. IT-MAIS/MAIS & 22 & 39 & 0.31 & 52 & 68 & 0.12 \\
\hline \multicolumn{7}{|c|}{ Ambient sound response } \\
\hline Detection & 30 & 71 & $0.05 *$ & 81 & 87 & 0.24 \\
\hline Identification & 15 & 48 & $0.05 *$ & 47 & 79 & $0.05^{*}$ \\
\hline Repetition & 10 & 35 & 0.17 & 17 & 54 & $0.05 *$ \\
\hline
\end{tabular}

*Statistically significant between G1 and G2 at each session time.

The largest changes between the two groups (G1 and G2) were found in animal sounds, environmental sounds, and two-syllable Spanish words at $40 \mathrm{~dB}_{\mathrm{HL}}$ (Table 4).For group $\mathrm{G} 1$, the $\mathrm{PTA}_{\mathrm{ECR}}$ of $38 \pm 6 \mathrm{~dB}_{\mathrm{HL}}$ seems to show better relationship with CST detection scores at $40 \mathrm{~dB}_{\mathrm{HL}}$ than PTA of $51 \pm 17 \mathrm{~dB}_{\mathrm{HL}}$ showed in Table 3 . The average hearing performance obtained for $\mathrm{G} 1$ and G2 groups was 32\% and 58\% respectively, $(p<0.05)$.

Below is an example of a patient (S2) older than 3 years, who is already familiar with the use of his CI, which has the audiometric and ECR thresholds of Figure 5 and the CST detection scores of Table 5.
According to audiometry patient S2 should detect all sounds at $40 \mathrm{~dB}_{\mathrm{HL}}$, however he is not. His CST detection scores are more related to ECR, where thresholds are below $40 \mathrm{~dB}_{\mathrm{HL}}$ only at some frequencies.

A common practice for CI fitting purposes is to use ECAP threshold to establish $\mathrm{M}$ and $\mathrm{T}$ levels of the dynamic range of electrical current for a limited number of intracochlear electrodes, without considering the CI sound processor operation. Unfortunately, ECAP is not a predictor of post-operative performance ${ }^{[27]}$. Some studies had shown that ECAP threshold tends to fall over time ${ }^{[11]}$, and is absent in approximately $5 \%$ of

TABLE 4. Average CST detection scores achieved for patients groups at T2 session.

\begin{tabular}{|c|c|c|c|c|c|c|}
\hline \multirow{2}{*}{$\begin{array}{l}\text { Test intensity } \\
\text { Patient group }\end{array}$} & \multicolumn{3}{|c|}{$60 \mathrm{~dB}_{\mathrm{HL}}[\%]$} & \multicolumn{3}{|c|}{$40 \mathrm{~dB}_{\mathrm{HL}}[\%]$} \\
\hline & $\begin{array}{c}\mathrm{G} 1 \\
(\mathrm{n}=8)\end{array}$ & $\begin{array}{c}\mathrm{G} 2 \\
(\mathrm{n}=10)\end{array}$ & $p$ & $\begin{array}{c}\mathrm{G} 1 \\
(\mathrm{n}=8)\end{array}$ & $\begin{array}{c}\mathrm{G} 2 \\
(\mathrm{n}=10)\end{array}$ & $p$ \\
\hline Ling sounds -extended version- & 78 & 94 & 0.41 & 39 & 78 & 0.07 \\
\hline Animal sounds & 77 & 95 & 0.17 & 39 & 75 & $0.05 *$ \\
\hline Transport sounds & 71 & 92 & 0.31 & 43 & 63 & 0.24 \\
\hline Ambient sounds & 74 & 94 & 0.12 & 38 & 74 & $0.05 *$ \\
\hline Two-syllable Spanish words & 63 & 92 & 0.17 & 23 & 58 & $0.05 *$ \\
\hline
\end{tabular}

*Statistically significant between G1 and G2 at each intensity. 
patients ${ }^{[12]}{ }^{[28]}$. ECAP thresholds profile does not fully coincide with $\mathrm{M}$ levels profile ${ }^{[12]}$, hence final $\mathrm{M}$ and $\mathrm{T}$ levels values should be confirmed by expert observation of the patient's auditory behavior and successive application of audiometry, which is not an easy task in pediatric patients.

\section{TABLE 5. Calibrated Sounds Test detection score for patient $\mathbf{S 2}$ in session $\mathrm{T} 2$.}

\begin{tabular}{|l|c|c|}
\hline Test intensity & $\mathbf{6 0} \mathbf{d B} \mathbf{H L}$ & $\mathbf{4 0} \mathbf{d B} \mathbf{H L}$ \\
\hline 1. Ling sounds -extended version- & $100 \%$ & $63 \%$ \\
\hline 2. Animal sounds & $100 \%$ & $99 \%$ \\
\hline 3. Transportation sounds & $100 \%$ & $57 \%$ \\
\hline 4. Ambient sounds & $100 \%$ & $90 \%$ \\
\hline 5. Two-syllable Spanish words & $100 \%$ & $64 \%$ \\
\hline
\end{tabular}

Bear in mind that audiometry was not originally designed for implanted patients. Thus, the standard test frequencies have no relationship with the frequency bands assigned to the intracochlear electrodes. This may cause to underestimate the hearing threshold by up to $3 \mathrm{~dB}$ when test frequency falls within the bandwidth of any band-pass filter or an inadequate estimation of hearing threshold if it falls outside bandwidth.

Due to its objective nature, ECR can be use since the initial CI programming. Furthermore, the utilization of sound stimulus of frequency equal to the central frequency assigned to each stimulation electrode allows individual addressing of intracochlear electrodes.

Additionally, ECR thresholds showed less dispersion than audiometry, probably due to its objective nature compared to the subjectivity of the audiometry which generated greater deviations.

The high variability found in the audiometry of the youngest patients, G1, may be due to their short age, limited experience using the $\mathrm{CI}$, and the difficulty they presented in performing the test.
In the other hand, it was difficult to obtain thresholds at high frequencies in these patients. For older children, G2, according to the audiometry, all of them would be in mild deafness, with hearing thresholds below $40 \mathrm{~dB}_{\mathrm{HL}}$, Figure 4, however the CST shows detection scores less than $80 \%$ for $40 \mathrm{~dB}_{\mathrm{HL}}$.

This is probably due to the fact that most patients have not developed the skills to detect the different sounds evaluated. G1 achieved a total CST detection score of $55 \%$ and $\mathrm{G} 2$ of $82 \%$ after approximately one year of CI use, Table 4.

The patient S2 hearing thresholds illustrate how the inherent subjectivity of audiometry affected the determination of hearing thresholds for test frequencies below $906 \mathrm{~Hz}$, where an average difference of $20 \mathrm{~dB}_{\mathrm{HL}}$ was observed with respect to the ECR thresholds after 8.4 months of CI activation (Figure 5).

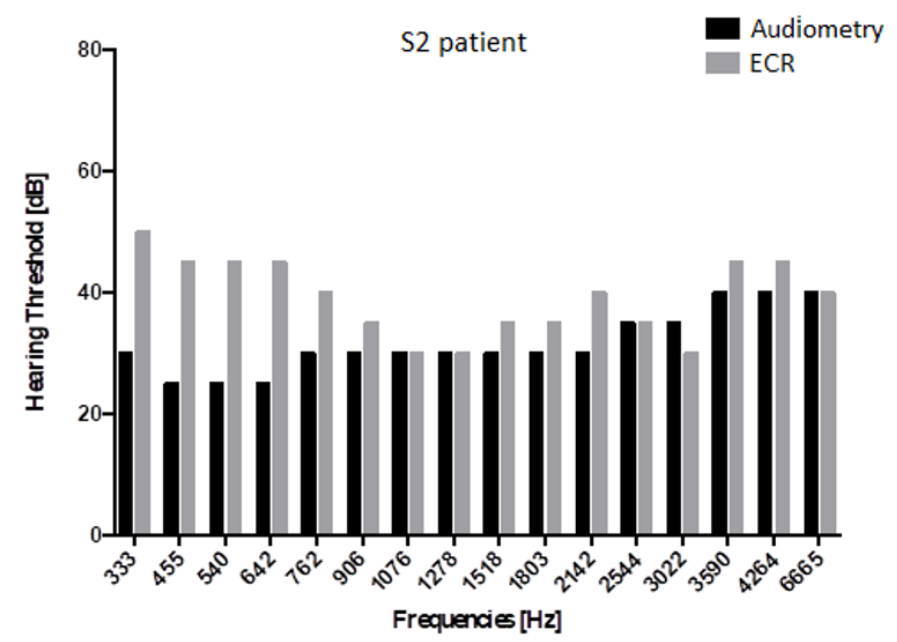

FIGURE 5. Audiometric and ECR thresholds obtained for patient $\mathbf{S} 2$ in session $\mathrm{T} 2$.

This study corroborated the feasibility of evaluating the patient-CI pair making the use of known frequency and variable intensity tone pips with the CI operating under everyday usage conditions, which take account of the effect of microphone sensitivity and sound processor gain. 
A limitation of the ECR test is that requires patients to remain asleep during the entire test. Nevertheless, the results showed the possibility of knowing the minimum sound intensity level for the detection of ECR corresponding to the probable hearing threshold. The relationship between patients' hearing performance improvement and ECR was also shown after modifying $\mathrm{T}$ and $\mathrm{M}$ levels, and/or extent of the dynamic range of electrical current derived from the amplitude and waveform analysis of the ECR.

The promising results provided in this study lead us to propose ECR as a tool for the evaluation and follow-up of CI users, especially for ages $\leq 3$ years. Although more studies are needed to show the possible benefits of this objective approach from the activation of the CI.

\section{CONCLUSIONS}

The most significant differences between audiometric and ECR thresholds obtained by PTA and PTA ${ }_{\mathrm{ECR}}$ were observed for patients aged 3 years or younger. Additionally, no statistically significant differences were obtained for older patients. However, the similarity in the threshold profiles obtained in both tests allows us to think about the possibility of obtaining hearing thresholds using ECR.

Furthermore, our study highlighted the limitations of audiometry to provide information on the hearing threshold due to subjectivity and the absence of a relationship between test frequencies and the central frequencies of the band pass filter assigned to each CI intracochlear electrode.

The application of ASQ and CST tests was very difficult due to the age of the patients and the lack of experience in the use of the $\mathrm{CI}$; however, these made possible to relate auditory behavior with audiometry and ECR, where a better relationship was shown between ASQ and CST scores and ECR thresholds.
This research project showed the possible benefits of employing ECR to estimate hearing thresholds per frequency in pediatric implanted patients, especially younger than 3 years, as well as the implementation of ASQ and CST to quantify hearing performance. During the patients' follow-up period, the methodology developed helped audiologists and therapists to identify some difficult situations related to CI programming and rehabilitation therapy strategy, helped them to quantify and improve the performance of their patients, and to have additional information about their hearing.

\section{ABBREVIATIONS}

» ASQ: Auditory Skills Questionnaire

» BSCMD: Bilateral Sensorineural Conductive Mixed Deafness

» BPSD: Bilateral Profound Sensorineural Deafness

» CI: cochlear implant

» CST: Calibrated Sounds Test

» ECR: Electrical Cochlear Response

» ECR threshold: hearing threshold estimated by ECR

» G1: patients group ages 3 years and younger

» G2: patients group older than 3 years

$\boldsymbol{H P} / \boldsymbol{F}$ : Hires-P w/Fidelity 120

» $\boldsymbol{H S} / \boldsymbol{F}$ : Hires-S w/Fidelity 120

»PTA: Pure Tone Average in the frequency range 500 to $2000 \mathrm{~Hz}$

» $\boldsymbol{P T A}_{\boldsymbol{E} \boldsymbol{C R}}$ : Pure Tone Average for ECR test in the frequency range 500 to $2000 \mathrm{~Hz}$

» T1: first evaluation sessions

» T2: second evaluation session.

\section{AUTHOR CONTRIBUTIONS}

A.K.Q. and J.M.C. contributed with the experimental design; data acquisition, analysis, and interpretation, and drafting the manuscript. In addition, A.K.Q. contributed with reviewing the manuscript and J.M.C contributed with critical revision of the manuscript and gave the final approval for publication. M.P.G. and 
N.E.B. contributed to the study design, data analysis and interpretation, critical revision of the manuscript, and gave the final approval for publication.

\section{ACKNOWLEDGMENTS}

This study is part of Agar Quintana's graduate research as a doctoral student in Biomedical Engineering at UAM-Iztapalapa, Mexico City. Her studies were supported by a grant from CONACyT. The authors thank patients and their parents for their kindly cooperation We also thank Dr. Maria E. Mena and Dr. Laura E.
Chamlati from the National Institute of Rehabilitation for their valuable support with patient's recruitment and following.

\section{ETHICAL STATEMENT}

Ethical Research Committee of National Institute of Rehabilitation (INR) approved and supervised the study complied with all applicable research and ethical standards and laws followed by the Declaration of Helsinki principles. All patients' parents signed informed consent. 


\section{REFERENCES}

[1] Flores-Beltran L. The Auditory-Verbal Therapy: a Trainning Program for Professionals in the Field of Hearing Disorders [Ph.D.'s thesis]. [Honolulu]: Atlantic International University, 2007. 251p.

[2] Manrique Rodríguez M, Huarte Irujo A. Organisation of a Cochlear Implant Programme. Acta Otorrinolaringol [Internet].

2013;64(1):55-67. Available from:

https://doi.org/10.1016/j.otoeng.2013.02.006

[3] Mitchell RM, Christianson E, Ramirez R, Onchiri FM, Horn DL, Pontis L, et al. Auditory comprehension outcomes in children who receive a cochlear implant before 12 months of age. Laryngoscope [Internet]. 2020;130(3):776-81. Available from: https://doi.org/10.1002/lary.28061

[4] Baudhuin J, Cadieux J, Firszt JB, Reeder RM, Maxson JL. Optimization of Programming Parameters in Children with the Advanced Bionics Cochlear Implant. J Am Acad Audiol [Internet]. 2012;23(5):302-12. Available from: https://doi.org/10.3766/jaaa.23.5.2

[5] Eisenberg LS. Clinical Management of Children With Cochlear Implants. 2nd ed. San Diego: Plural Publishing Inc; 2009. 890p.

[6] Guenser G, Laudanski J, Phillipon B, Backus BC, Bordure P, Romanet $\mathrm{P}$, et al. The relationship between electrical auditory brainstem responses and perceptual thresholds in Digisonic ${ }^{\circledR}$ SP cochlear implant users. Cochlear Implants Int [Internet]. 2015;16(1):32-8. Available from: https://doi.org/10.1179/1754762814Y.0000000082

[7] Lira De Andrade KC, De Caevalho Leal M, Ferreira Muniz L, De Lemos Menezes P, Gomes De Albuquerque KM, Tenório A. The importance of electrically evoked stapedial reflex in cochlear implant. Braz J Otorhinolaryngol [Internet]. 2014;80(1):68-77. Available from: https://doi.org/10.5935/1808-8694.20140014

[8] Gattaz G, Battmer RD, Lehnhardt E, Gnadeberg D. [Correlation between electrically-induced stapedius reflex and discomfort threshold in cochlear implant patients]. HNO [Internet]. 1992;40(12):480-3. German. Available from: https://pubmed.ncbi.nlm.nih.gov/1493968/

[9] Van Den Abbeele T, Noël-Petroff N, Akin I, Caner G, Olgun L, Guiraud J, et al. Multicentre investigation on electrically evoked compound action potential and stapedius reflex: how do these objective measures relate to implant programming parameters? Cochlear Implants Int [Internet]. 2012;13(1):26-34. Available from: https://doi.org/10.1179/1754762810Y.0000000001

[10] Walkowiak A, Lorens A, Polak M, Kostek B, Skarzynski H, Szkielkowska A, et al. Evoked Stapedius Reflex and Compound Action Potential Thresholds versus Most Comfortable Loudness Level: Assessment of Their Relation for Charge-Based Fitting Strategies in Implant Users. ORL [Internet]. 2011;73(4):189-95. Available from: https://doi.org/10.1159/000326892

[11] Marsella P, Scorpecci A, Pacifico C, Resca A, Vallarino MV, Ingrosso A, et al. Safety and Functional Results of Early Cochlear Implant Switch-On in Children. Otol Neurotol [Internet]. 2014;35(2):277-82. Available from: https://doi.org/10.1097/mao.0000000000000259
[12] Botros A, Banna R, Maruthurkkara S. The next generation of Nucleus ${ }^{\circledR}$ fitting: a multiplatform approach towards universal cochlear implant management. Int J Audiol [Internet]. 2013;52(7):485-94. Available from: https://doi.org/10.3109/14992027.2013.781277

[13] American Speech-Language-Hearing Association. Guidelines for Methods for Manual Pure-Tone Threshold Audiometry [Internet]. New York: Acoustical Society of America; 2004. Available from: https://www.asha.org/policy/gl2005-00014/

[14] Caner G, Olgun L, Gültekin G, Balaban M. Optimizing Fitting in Children Using Objective Measures Such as Neural Response Imaging and Electrically Evoked Stapedius Reflex Threshold. Otol Neurotol [Internet]. 2007;28(5):637-40. Available from: https://doi.org/10.1097/mao.0b013e3180577919

[15] Katz J. Hand book of clinical audiology. 7th ed. Philadelphia: Wolters Kluwer; 2009. 927p.

[16] Cosetti M, Shapiro W, Green J, Roman B, Lalwani A, Gunn S, et al. Intraoperative Neural Response Telemetry as a Predictor of Performance. Otol Neurotol [Internet]. 2010;31(7):1095-9. Available from: https://doi.org/10.1097/mao.0b013e3181ec1b8c

[17] Gifford RH. Cochlear Implant Patient Assessment: Evaluation of Candidacy, Performance, and Outcomes. 2nd ed. San Diego: Plural Publishing Inc; 2020. 189p.

[18] Cornejo Cruz JM, Granados Trejo MP, inventors; Systems and methods for detecting and using an electrical cochlear response ("ECR") in analyzing operation of a cochlear stimulation system. WO2010041920A1. 2010. Spanish.

[19] Quintana A, Beltran N, Granados PM, Chamlati E, Mena M, Cornejo JM. Objective Approach to Audiometry in the Pediatric Implanted Patient. In: Braidot A, Hadad A. (eds.). VI Latin American Congress on Biomedical Engineering CLAIB 2014 [Internet]. Paraná, Argentina: IFMBE Proceedings, Springer Cham. 2014;49:707-10. Available from: https://doi.org/10.1007/978-3-319-13117-7_180

[20] Cavicchiolo S, Mozzanica F, Guerzoni L, Murri A, Dall'Ora I, Ambrogi F, et al. Early prelingual auditory development in Italian infants and toddlers analysed through the Italian version of the Infant-Toddler Meaningful Auditory Integration Scale (IT-MAIS). Eur Arch Otorhinolaryngol [Internet]. 2018;275(2):615-22. Available from: https://doi.org/10.1007/s00405-017-4847-6

[21] Dos Santos Pedrett M, Pedrett Costa MB. Application of RDLS scale to characterize oral language profiles in children using cochlear implant. CoDAS [Internet]. 2019; 31(5):1-7. Portuguese. Available from: https://doi.org/10.1590/2317-1782/20192018158

[22] Klem GH, Lüders HO, Jasper HH, Elger C. The ten-twenty electrode system of the International Federation. The International Federation of Clinical Neurophysiology. Electroencephalogr Clin Neurophysiol Suppl. 1999;52:3-6. 
[23] Fu Y, Chen Y, Xi X, Hong M, Chen A, Wang Q, Wong L.

[Development of early auditory and speech perception skills within one year after cochlear implantion in prelingual deaf children].

Zhonghua Er Bi Yan Hou Tou Jing Wai Ke Za Zhi. 2015;50(4):274-80. Chinese.

[24] Ling D. Speech and the hearing-impaired child Theory and Practice. Washington: The Alexander Graham Bell Association'for the Deaf. Inc; 1976. 402p.

[25] Archbold S. Organisation of the Nottingham Paediatric Cochlear Implant Programme. Central East Eur J. 1996;1(1):20-7.

[26]
[27] El Shennawy AM, Mashaly MM, Shabana MI, Sheta SM. Telemetry changes over time in cochlear implant patients. Hear Balance Commun [Internet]. 2016;13(1):24-31. Available from: https://doi.org/10.3109/21695717.2014.999427

[28] Moura ACG, Goffi-Gomez MVS, Couto MIV, Brito R, Tsuji RK, BefiLopes DM, et al. Longitudinal Analysis of the Absence of Intraoperative Neural Response Telemetry in Children using Cochlear Implants. Int Arch Otorhinolaryngol [Internet]. 2014;18(4):362-8. Available from: https://doi.org/10.1055/s-0034-1372510
NCSS Software. NCSS 9 Statistical Software. Kaysville, Utah, USA. 2013. 